\title{
Ultrastructural study of pleural fluid in mesothelioma
}

\author{
M. LE G R A D a n d R. PAR I E N T E \\ Laboratoire de Cytologie et d'Histologie Pulmonaire, Clinique de Pneumo-phtisiologie, \\ Hôpital Laennec, Paris 7
}

\begin{abstract}
Legrand, M. and Pariente, R. (1974). Thorax, 29, 164-171. Ultrastructural study of pleural fluid in mesothelioma. By means of electron microscopy, three types of malignant cell can be identified in the pleural fluid of patients with pleural mesothelioma. These cell types are described, and the use of cytology in the differential diagnosis of pleural effusion is discussed.
\end{abstract}

The differentiation of primary from secondary pleural tumours often proves very difficult using only light microscopy. The greater resolving power of the electron microscope has enabled the two types of pleural tumours to be more readily distinguished. The advantages and disadvantages of pleural fluid examination for malignant pleural mesothelioma cells is discussed.

\section{MATERIAL AND METHODS}

Thirty-two pleural fluids were examined by electron microscopy from patients with malignant pleural tumours. Nine of these cases were patients judged to have malignant pleural mesotheliomas, and in all, 22 specimens were examined from this group and form the basis for this report.

The criteria on which the diagnosis of a pleural mesothelioma was based included $(a)$ the absence of any other source of a primary tumour during the clinical course of the disease, $(b)$ the local or generalized spread of the tumour within the pleural cavity, (c) the light microscopic appearances of the tumours, and $(d)$ the absence of any other primary tumour at a subsequent necropsy examination.

Heparinized pleural fluid was centrifuged at 2000 $\mathrm{rev} / \mathrm{min}$ for 10 minutes and the precipitated pellet of cells was fixed in $2 \cdot 7 \%$ glutaraldehyde for 24 hours at $4^{\circ} \mathrm{C}$. If there was a failure of the cells to form a compact pellet the cells were suspended in bovine serum albumen solution to which was added $1 \mathrm{ml}$ of $25 \%$ glutaraldehyde and were re-centrifuged. The pellet of cells was then embedded and ultrathin sections were prepared and stained with uranyl acetate and lead citrate. Thin $1.0 \mu$ sections were also stained with Paragon stain and examined by light microscopy.

\section{RESULTS}

The proportion of tumour cells to macrophages, lymphocytes, and red blood cells varies greatly in different specimens. Three types of malignant pleural mesothelioma cells were identified. The first (Fig. 1) was the most characteristic, a mature malignant mesothelial cell which showed features common to non-neoplastic mesothelial cells (Fig. 2). It varied from 10-15 $\mu$ in diameter, was regular and rounded and contained a nucleus with one or more irregular nucleoli. The cytoplasm contained mitochondria, lightly stained, rounded inclusions, possibly lipid in nature, smooth and rough endoplasmic reticulum, and peripherally situated glycogen granules. There were numerous microvilli projecting from the cell wall, similar to those present in normal mesothelial cells. These cells were usually numerous, and clumps of the cells were joined by desmosomes.

The second variety of cell type (Fig. 3) was elongated with a large irregular nucleus contain- $\bar{N}$ ing numerous chromatin particles. The nucleus 5 also contained lightly stained bodies and a promi- $\tilde{O}$ nent nucleolus. The cytoplasm contained damaged $\underset{\omega}{N}$ mitochondria and some endoplasmic canals and $\bar{O}$ there were numerous, often long and sinuous 0 microvilli projecting from the cell membrane. $\stackrel{\leftarrow}{\Phi}$ These cells were scanty, occurring singly or in $\stackrel{\infty}{+}$ small groups in the pleural fluid.

The third type of cell (Fig. 4) was rounded with a pale nucleus containing little chromatin or $\mathbb{\AA}$ nucleolar remnants. The cytoplasm contained en- $\mathbb{D}$ doplasmic canals and degenerate mitochondria and the cell membrane was devoid of microvilli. 


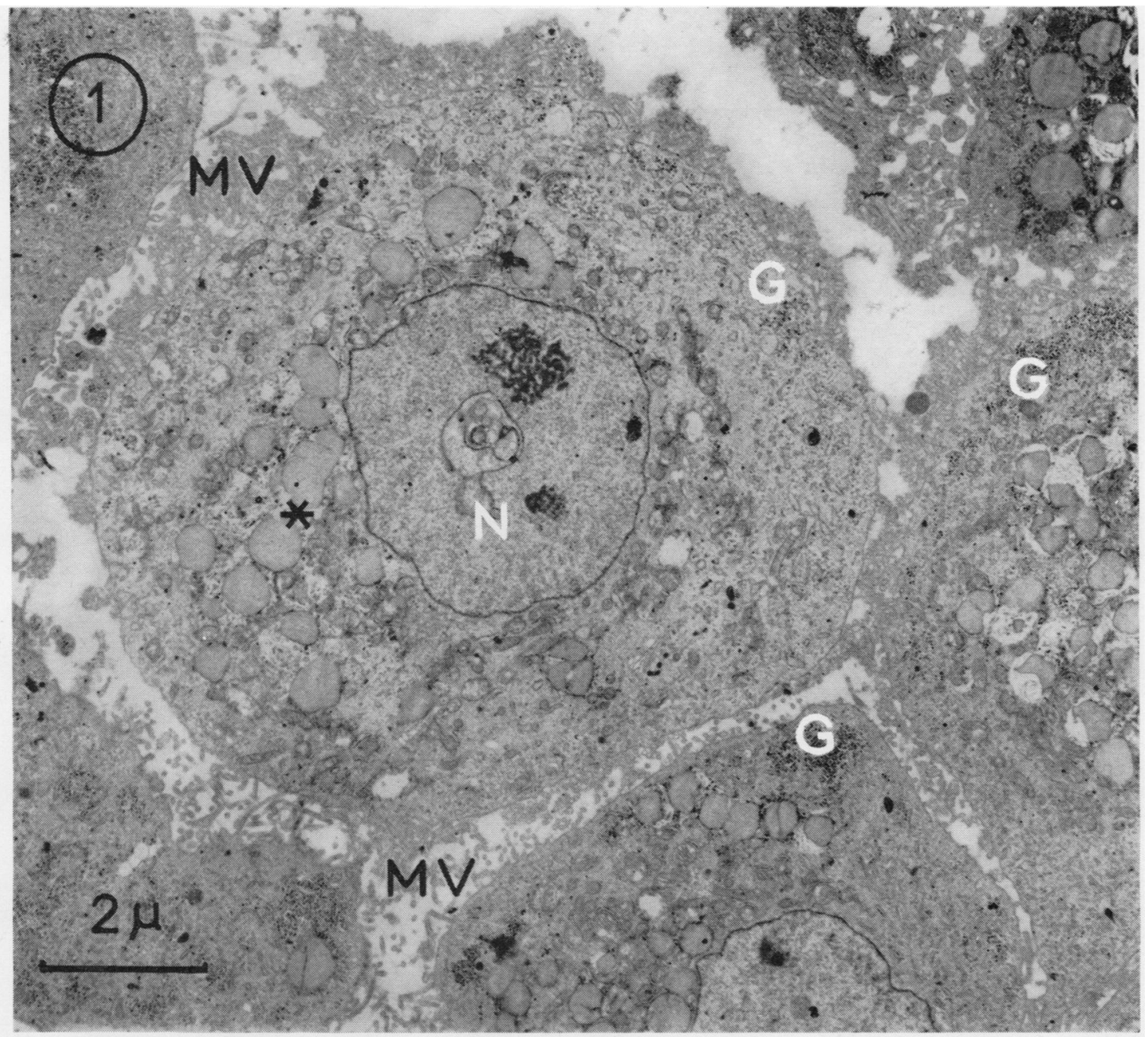

FIG. 1. Type 1 cells $(\times 5,900)$. Nucleus with cytoplasmic inclusions $(N)$; fibrillary area with normal or impaired mitochondria $\left({ }^{*}\right)$; glycogen $(G)$; microvilli $(M V)$. 


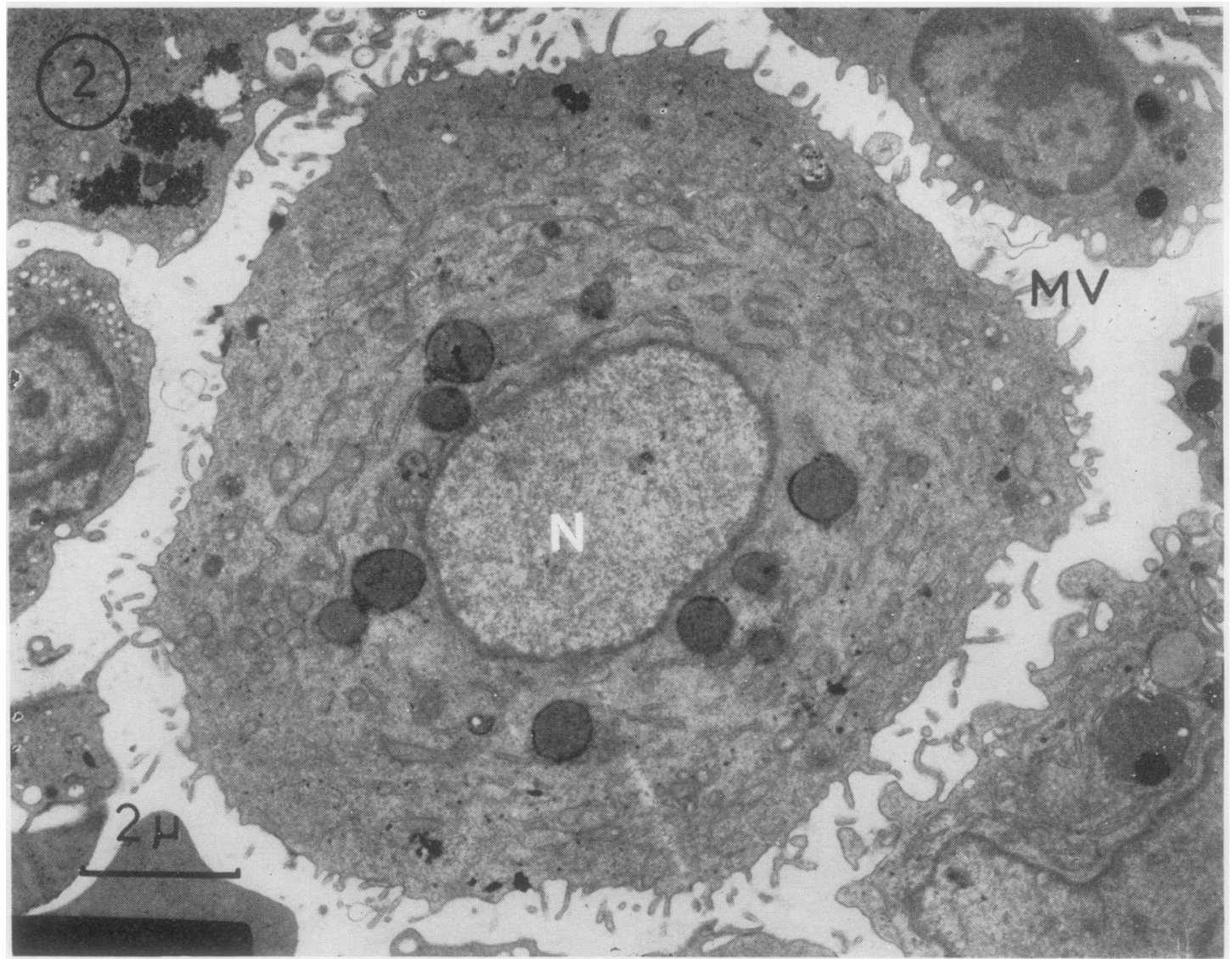

FIG. 2. Free mesothelial cell in benign pleural effusion $(\times 5,165)$. 


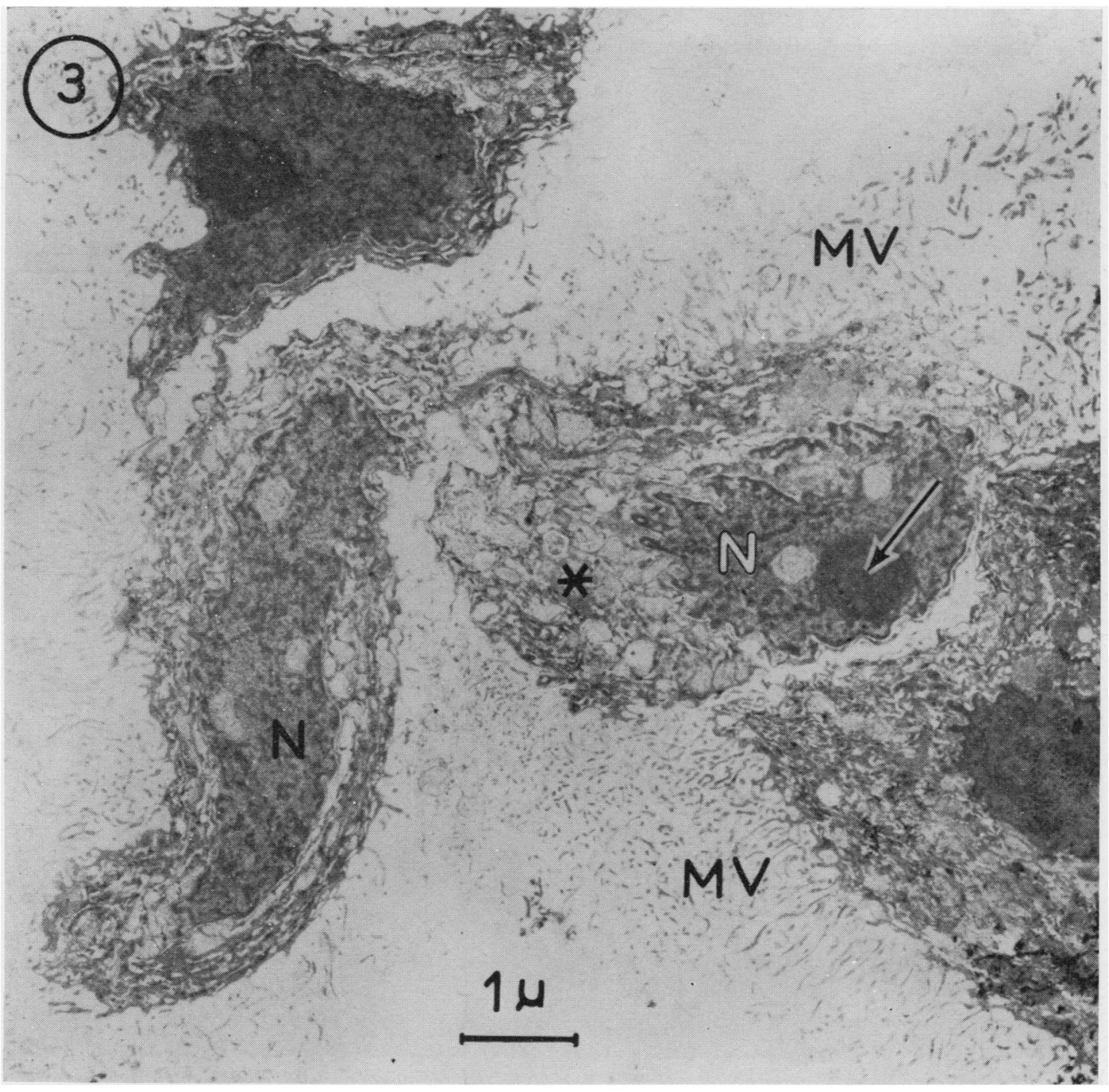

FIG. 3. Type 2 cells $(\times 4,435)$. Nucleus with dense striped chromatin $(N)$; nucleolus $(\rightarrow)$; heterogeneous cytoplasm with impaired mitochondria $\left({ }^{*}\right)$; microvilli $(M V)$. 


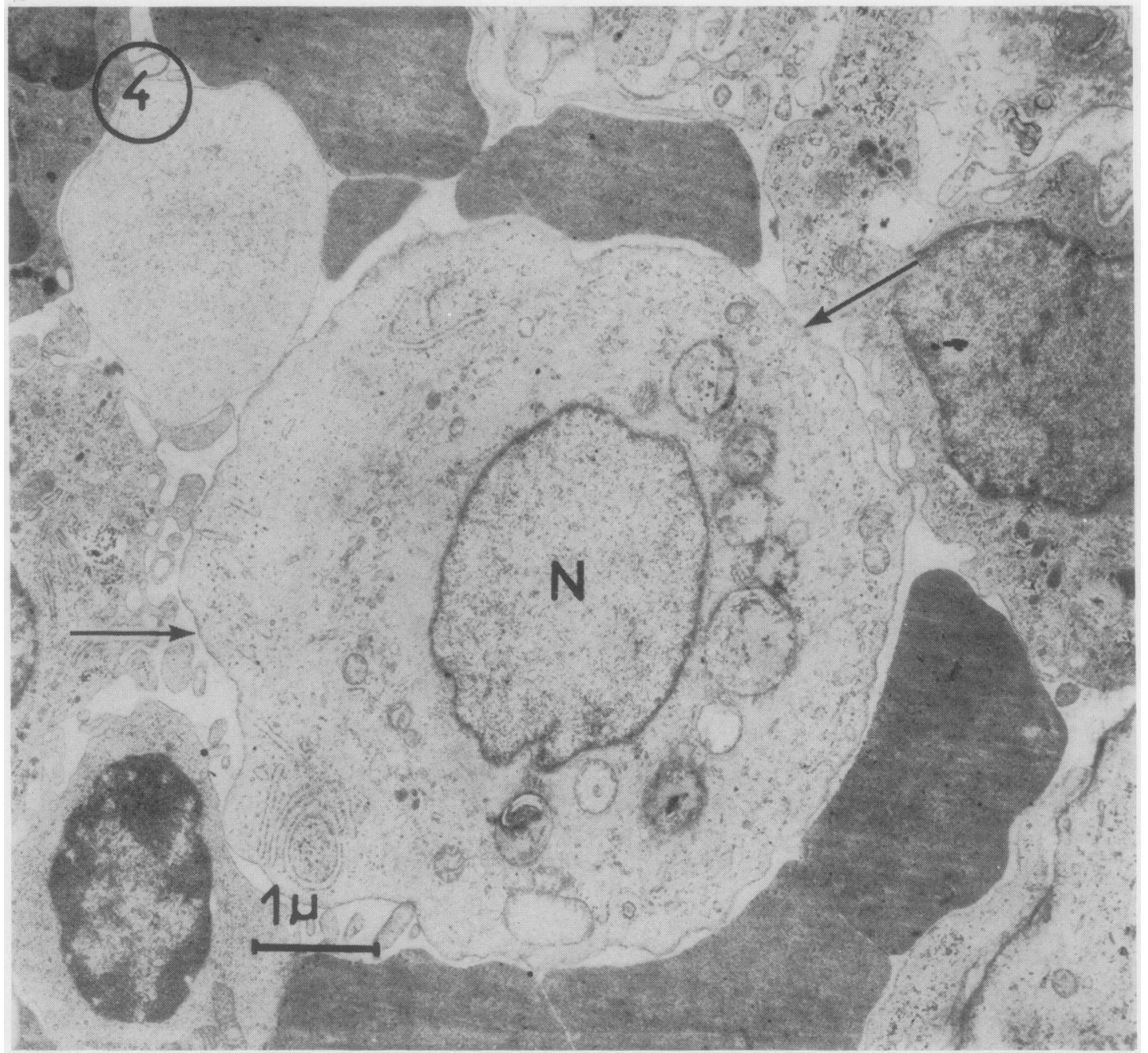

FIG. 4. Third cell type-undifferentiated cell $(\times 4,350)$. Nucleus $(N)$ with scraps of nucleoli; regular cell membrane without microvilli $(\rightarrow)$. 


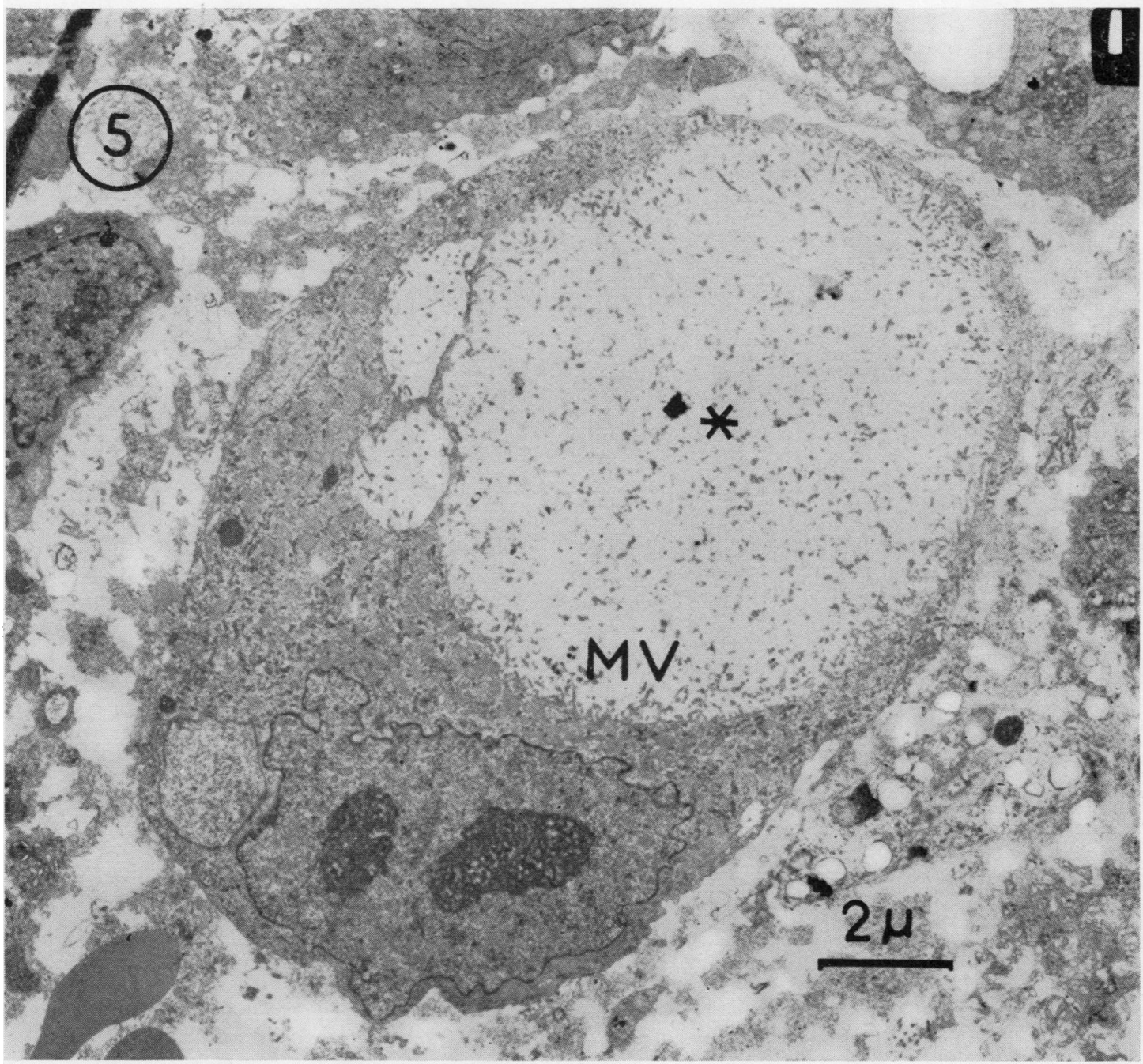

FIG. 5. Malignant cell with large central vacuole $\left(^{*}\right)$ edged by numerous microvilli $(M V)(\times 4,500)$. 
FIG. 6. Macrophagic activity $(\rightarrow)$ in a malignant effusion without tumour cells $(\times 5,600)$.

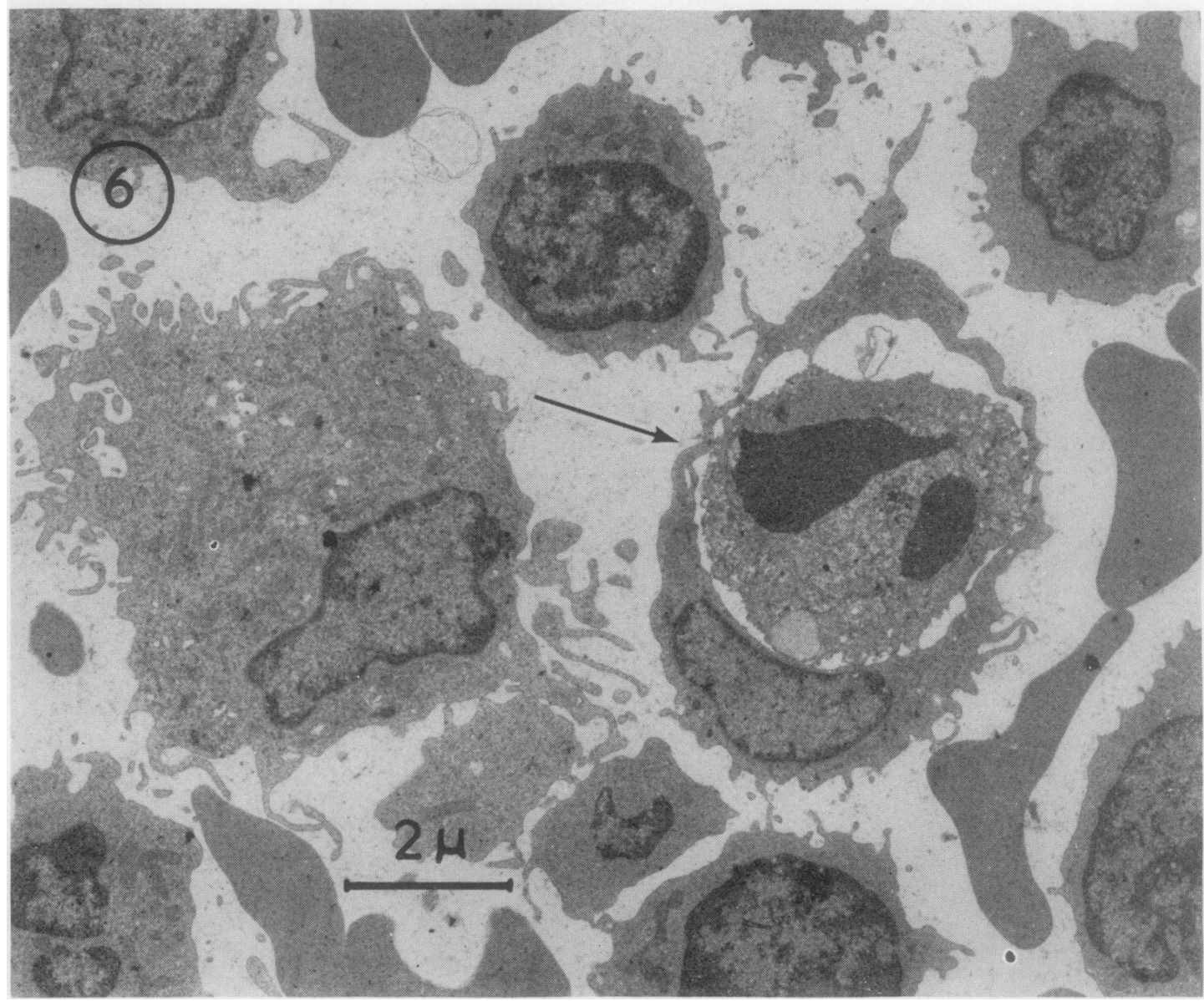


This variety of cell was regarded as an undifferentiated malignant pleural cell and occurred as either an isolated cell or a small group of cells without any cell junctions.

Some cells, but especially the second type, showed extensive cytoplasmic vacuoles. These vacuoles (Fig. 5) were neither phagosomal nor probably caused by enzymic digestion as the inner wall of the vacuole was fringed with microvillous processes. A further feature seen in pleural fluid from cases of mesothelioma and pleural secondary growth was phagocytosis of lymphocytic and damaged phagocytes, an unusual finding in pleural fluid caused by non-neoplastic conditions (Fig. 6).

\section{COMMENT}

Repeated examinations of the pleural fluid revealed one or more of the malignant cell types described. The type 2 cells were the most common, though type 1 cells most closely resembled normal pleural mesothelial cells (Legrand et al., 1971; Luse and Spjut, 1964). Repeated examinations showed that type 1 cells may transform into type 2 cells, thus demonstrating their common origin. The type 2 cells closely resembled fibroblasts and demonstrated the ability of malignant mesothelial cells to transform into that cell type (Kay and Silverberg, 1971). Undifferentiated type 3 cells were also found during repeated examinations to transform into the more readily identifiable type 1 or 2 malignant mesothelial cells, thus enabling the pleural origin of the tumour to be recognized.

Pleural fluid may act as a culture medium for the malignant cells and they are probably capable of undergoing differentiation in it similar to the changes described in vitro by Stout and Murray (1942).

Repeated examinations of cells in pleural fluid, unlike lung drill and open surgical biopsy, is readily and easily performed. Preliminary light microscopic examination of thin $1 \mu$ sections prior to the preparation of ultra thin sections enables cell-rich areas to be chosen for the preparation of the latter. Although false positive results are uncommon, normal mesothelial cells need to be differentiated from malignant mesothelium, and poorly preserved cells should be disregarded. Whenever clinical indications suggest a malignant pleural tumour, repeated examination of the pleural fluid should be made and the discovery of numerous active phagocytes in the fluid should prompt further and careful examination for malignant cells.

\section{REFERENCES}

Kay, S. and Silverberg, S. G. (1971). Ultrastructural studies of a malignant fibrous mesothelioma of the pleura. Archives of Pathology, 92, 449.

Legrand, M., Pariente, R., André-Bougaran, J., Chretien, J., and Brouet, G. (1971). Ultrastructure de la plèvre pariétale humaine. Presse Médicale, 79, 2515.

Luse, S. A. and Spjut, H. J. (1964). An electron micrscopic study of a solitary pleural mesothelioma. Cancer, 17, 1546.

Stout, A. P. and Murray, M. R. (1942). Localized pleural mesothelioma. Archives of Pathology, 34, 951.

Requests for reprints to: Dr. M. Legrand, Centre de Pneumologie, Hôpital Beaujon, 92 Clichy, France. 